\title{
Mobile phone radiation might alter protein expression in human skin
}

\author{
Anu Karinen, Sirpa Heinävaara, Reetta Nylund and Dariusz Leszczynski*
}

Address: STUK - Radiation and Nuclear Safety Authority, Laippatie 4, 00880 Helsinki, Finland

Email: Anu Karinen - anu.karinen@stuk.fi; Sirpa Heinävaara - sirpa.heinavaara@stuk.fi; Reetta Nylund - reetta.nylund@stuk.fi; Dariusz Leszczynski* - dariusz.leszczynski@stuk.fi

* Corresponding author

Published: II February 2008

BMC Genomics 2008, 9:77 doi:10.1 |86/|47|-2/64-9-77

This article is available from: http://www.biomedcentral.com/I47/-2/64/9/77

(c) 2008 Karinen et al; licensee BioMed Central Ltd.

This is an Open Access article distributed under the terms of the Creative Commons Attribution License (http://creativecommons.org/licenses/by/2.0), which permits unrestricted use, distribution, and reproduction in any medium, provided the original work is properly cited.
Received: 13 November 2007

Accepted: II February 2008

\begin{abstract}
Background: Earlier we have shown that the mobile phone radiation (radiofrequency modulated electromagnetic fields; RF-EMF) alters protein expression in human endothelial cell line. This does not mean that similar response will take place in human body exposed to this radiation. Therefore, in this pilot human volunteer study, using proteomics approach, we have examined whether a local exposure of human skin to RF-EMF will cause changes in protein expression in living people.

Results: Small area of forearm's skin in 10 female volunteers was exposed to RF-EMF (specific absorption rate $S A R=1.3 \mathrm{~W} / \mathrm{kg}$ ) and punch biopsies were collected from exposed and nonexposed areas of skin. Proteins extracted from biopsies were separated using 2-DE and protein expression changes were analyzed using PDQuest software. Analysis has identified 8 proteins that were statistically significantly affected (Anova and Wilcoxon tests). Two of the proteins were present in all 10 volunteers. This suggests that protein expression in human skin might be affected by the exposure to RF-EMF. The number of affected proteins was similar to the number of affected proteins observed in our earlier in vitro studies.
\end{abstract}

Conclusion: This is the first study showing that molecular level changes might take place in human volunteers in response to exposure to RF-EMF. Our study confirms that proteomics screening approach can identify protein targets of RF-EMF in human volunteers.

\section{Background}

Physiological functions of human body are regulated by electric currents. Therefore, is not surprising that placing human body within electromagnetic field, of sufficient strength, may affect physiological processes. The possibility of induction of biological and health effects by low energy radiation emitted by mobile phones (radiofrequency-modulated electromagnetic fields: RF-EMF) remains a controversial issue. In spite of years of research, there is still ongoing discussion whether RF-EMF could induce any physiologically relevant effects [1]. The vast majority of the so far conducted research has focused on cancer. However, RF-EMF is also suspected as potential cause of such ailments as sleep disorders, headaches or allergy-like symptoms [2].

We have proposed that proteomics screening may be used to reveal molecular targets of RF-EMF and help to understand the possible biochemical mechanism of the RFEMF-induced effects [3]. Our earlier proteomics studies have shown that changes in protein expression and activity (phosphorylation) were induced in human endothe- 
lial cell line EA.hy926 that was exposed to RF-EMF [4-7]. These in vitro observed effects, however, do not automatically mean that similar changes would happen in the cells of mobile phone users. Therefore, the present pilot study was undertaken to determine whether a local exposure of human skin to RF-EMF will induce any changes in protein expression and whether it will be possible to find common protein(s) that respond to RF-EMF in all volunteers.

\section{Results}

Ethical permit to perform this study was obtained from the Ethics Committee of Department of Surgery of Hospital District of Helsinki and Uusimaa, Finland. A small skin area of a forearm of 10 of same sex (female) volunteers (age 27 - 65 years; mean 51 years) were irradiated for 1 hour with $900 \mathrm{MHz}$ GSM signal at specific absorption rate (SAR) of $1.3 \mathrm{~W} / \mathrm{kg}$, using specially designed exposure setup [8]. The mobile phone safety limit SAR is $2.0 \mathrm{~W} / \mathrm{kg}$, as recommended by the International Commission on Non-Ionizing Radiation Protection (ICNIRP).

Immediately after the exposure, a punch biopsy of the exposed area of skin (experimental sample) was taken by a physician. Another punch biopsy was taken from the other, non-exposed, forearm (sham sample). In this experimental set-up each volunteer acted as its own sham control. Both exposed and non-exposed skin samples of all volunteers were immediately snap-frozen in liquid nitrogen and stored before extraction of proteins.

Proteins from all samples were extracted using TRIzol Reagent (Invitrogen) and separated using 2-dimensional gel electrophoresis (2-DE) with $\mathrm{pH}$ gradient range of 4-7 in the first dimension and 9\% SDS-PAGE gel in the second dimension (GE Healthcare). Proteins were detected by silver staining and spot distribution pattern was analyzed using PDQuest 7.2 software (Bio-Rad).

We have analyzed a fragment of proteome: proteins with the isoelectric point (pI) 4-7 and the molecular weight $<40 \mathrm{kDa}$, because the protein spot separation in 2-DE in this area was clearly distinguishable (Figure 1). Firstly, using PDQuest software, for each volunteer was generated an artificial gel, by combining protein expression profiles from sham and exposed samples. Thereafter, all 10 artificial gels were combined into single artificial master gel

\section{Isoelectric point (pI)}

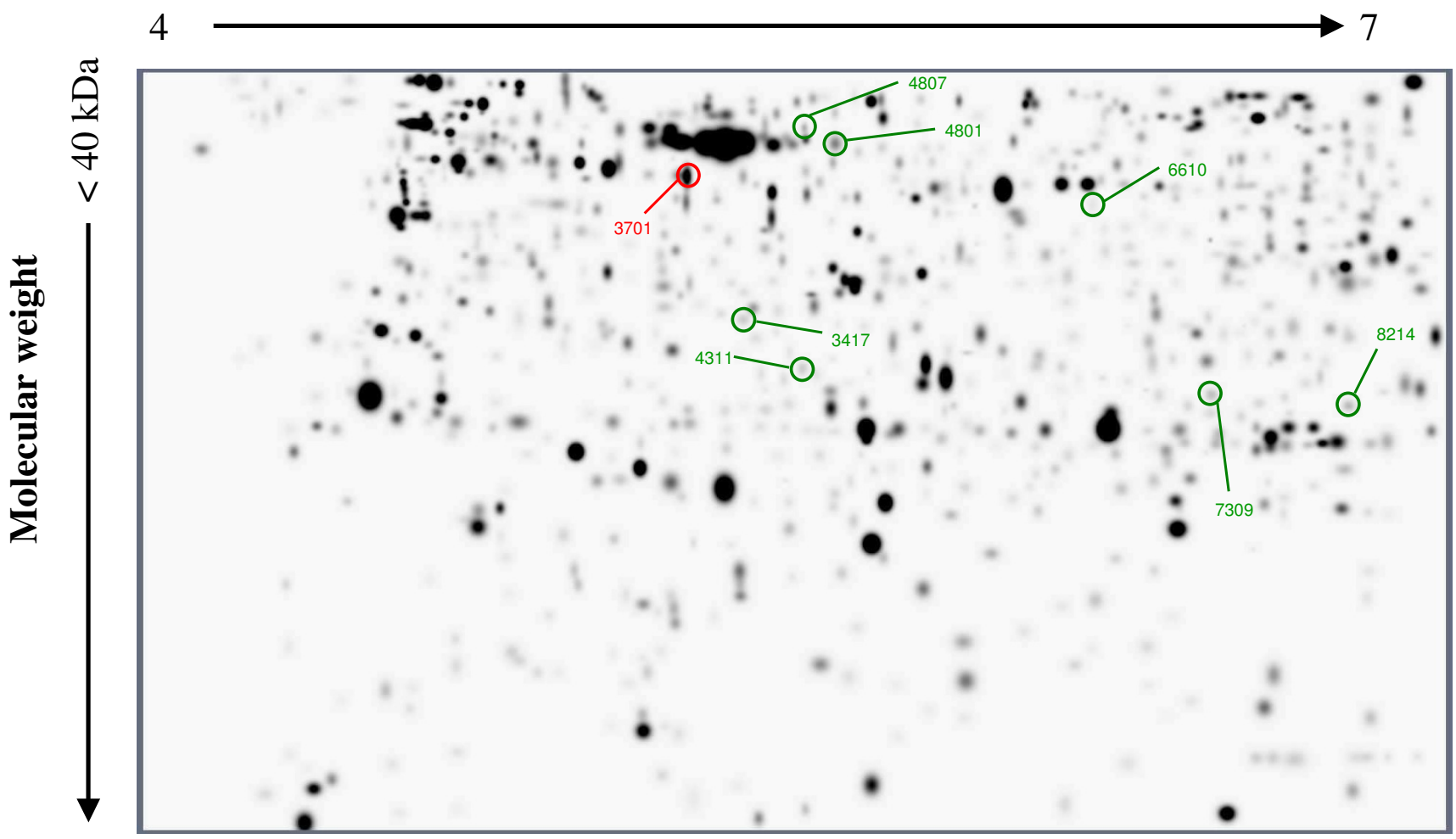

\section{Figure I}

Artificial master gel for all sham and exposed skin samples of all 10 volunteers. Statistically significantly affected protein spots are marked in red color (declined expression) and in green color (increased expression). 
and the differentially expressed protein spots, which were detected in at least 4 volunteers, were statistically analyzed.

The ratio of exposed and sham sample expression was analyzed spot by spot, after logarithm transformation, with variance analysis (anova). Due to small numbers and potential violations of model assumptions, the ratios were also studied with the Wilcoxon test. The statistical analysis has identified 8 differentially expressed proteins where the change in expression was statistically significant among the 579 identified proteins spots (Table 1). Two of the protein spots (\#3701, \#4801) were present in all 10 volunteers thus showing that it is possible to find common, responding proteins among the all volunteers. The p-values are not adjusted for multiple comparisons.

\section{Discussion}

Proteomics approach to study effects of mobile phone radiation on cells has been used so far only by two research groups, ours in Helsinki and group the Zhejiang University, Hangzhou, China. Our studies, using human endothelial cell lines have shown that mobile phone radiation induces statistically significant changes in the expression of several tens of proteins [6] and that the response of cell might be proteome-dependent [7]. In one study, the group in China has not found statistically significant differences in protein expression in MCF-7 cells [9]. The reason for it might be too low number of experiments in MCF-7 study [9]. In our studies statistical analysis was based on 10 different experiments whereas Zeng et al. [9] based their analysis on only three replicates. Another reason for the difference might be different sensitivity of MCF-7 cells as compared with ours endothelial cell lines EA.hy926 and EA.hy926v1. In the other study from Zhejiang University [10] were found 4 differentially expressed proteins in lens epithelial cells, among them the stress response protein Hsp70.
The obtained results, suggesting effect of mobile phone radiation on protein expression in human cell lines, do not automatically mean that this exposure will have any effect on protein expression in humans. The so far conducted human volunteer studies have focused on cognitive responses to RF-EMF [2] and there is no information available about the proteome, as well as transcriptome, response to mobile phone radiation in humans. This study is, to our knowledge, the first one where human response to RF-EMF was examined on molecular level. Our results suggest that human skin might respond to RF$\mathrm{EMF}$ and change protein expression profile. Interestingly, when adjusting results of our previous cellular study [6] using the size of proteome analyzed in the present study (pI $4-7 ;<40 \mathrm{kDa}$ ) the number of the statistically significantly affected proteins appears to be similar in this and in earlier [6] study, 8 spots and 9 spots, respectively. The number of differentially expressed protein spots in both studies is below the number of expected false positives. However, as we have demonstrated experimentally [6] and discussed previously [11] it is likely that some of the proteins will be indeed, real positives. However, without further testing, it is not possible to predict whether these changes will have impact on skin physiology.

Finally, our study confirms that the proposed by us proteomics approach [3] can identify protein targets of RFEMF. This approach to EMF research has been subsequently accepted by the EMF scientists [12,13] and has been included into the 2006 World Health Organization Research Agenda [14]. However, new and larger study is urgently needed to strengthen our pilot observations and to determine what impact mobile phone exposure might have on human tissues.

\section{Conclusion}

é Mobile phone radiation might alter protein expression in human skin.

Table I: List of proteins that were present in at least 4 volunteers and which expression has been changed in statistically significant manner $(<0.05)$ as determined by the variance analysis and the Wilcoxon test. Ratio $=$ exposed sample expression/sham sample expression.

\begin{tabular}{|c|c|c|c|c|c|c|c|}
\hline & Protein spot \# & Prevalence of spot* & $\begin{array}{r}\begin{array}{r}\text { Average of } \\
\text { ratio }\end{array}\end{array}$ & $\begin{array}{r}\text { Standard } \\
\text { deviation of ratio }\end{array}$ & $\begin{array}{r}\begin{array}{r}\text { Median of } \\
\text { ratio }\end{array}\end{array}$ & Anova p-value & Wilcoxon p-value \\
\hline I. & 3417 & 4 & 117.35 & 157.93 & 1.00 & $0.0370^{+}$ & 0.0474 \\
\hline 2. & 3701 & 10 & 0.68 & 0.39 & 0.49 & 0.0139 & 0.0367 \\
\hline 3. & 4311 & 7 & 68.88 & 134.67 & 1.71 & 0.0369 & 0.0169 \\
\hline 4. & 4801 & 10 & 1.89 & 1.01 & 1.42 & 0.0162 & 0.0218 \\
\hline 5. & 4807 & 5 & 223.17 & 302.78 & 1.53 & $0.0307^{+}$ & 0.0277 \\
\hline 6. & 6610 & 4 & 39.86 & 52.05 & 1.00 & $0.0371^{+}$ & 0.0474 \\
\hline 7. & 7309 & 8 & 67.38 & 101.44 & 12.17 & 0.0034 & 0.0076 \\
\hline 8. & 8214 & 4 & 146.60 & 252.75 & 1.00 & $0.0391^{+}$ & 0.0474 \\
\hline
\end{tabular}

\footnotetext{
* prevalence shows in how many volunteers, out of 10, was detected given protein spot;
}

+ variance analysis might be unreliable because of small numbers of cases and potential violations of model assumptions; 
é Physiological significance of this change is not known and requires further study.

é Larger human volunteer study will be needed to confirm results of this pilot study.

é Proteomics screening is valid method for search for molecular targets of mobile phone radiation. Without this approach the identification of the proteins responding to mobile phone radiation would not be reasonably possible.

\section{Methods}

\section{Ethical issues}

Ethical permit to perform this study was obtained, in accordance with the Helsinki Declaration, from the Ethics Committee of the Department of Surgery of the Hospital District of Helsinki and Uusimaa, Finland (decision \#127/2005 issued on November 23, 2005). Each volunteer was informed in detail about all experimental procedures and each of them has signed the informed consent form (in Finnish language).

\section{Exposure of volunteers to mobile phone radiation}

Volunteers were exposed to $900 \mathrm{MHz}$ GSM mobile phone radiation in an experimental setup described in detail elsewhere [8]. The source of irradiation was a half-wave dipole fed with a computer controlled GSM phone. The specific absorption rate (SAR) induced in the skin was 1.3 $\mathrm{W} / \mathrm{kg}$ what is below the ICNIRP safety guidelines $(2.0 \mathrm{~W} /$ $\mathrm{kg}$ ). During the exposure small area of the right forearms was irradiated for one hour. The other, non-irradiated forearm was used as sham control. Immediately after exposure skin punch-biopsies were taken from the exposed and non-exposed skin for protein analysis.

\section{Protein extraction from skin biopsies}

Skin punch biopsies, consisting of both dermis and epidermis but without the underlying fat tissue, were frozen immediately after harvesting in liquid nitrogen and stored at $-80^{\circ} \mathrm{C}$. Isolation and separation of proteins were performed in the blinded manner. Proteins were isolated from frozen skin using TRIzol $^{\oplus}$ reagent protocol as described by the manufacturer (Invitrogen, Carlsbad, CA, USA) with a few modifications. Briefly, the chopped skin punch-biopsies were immersed in $0.5 \mathrm{ml}$ of ice-cold TRIzol reagent and homogenized on ice with 70 strokes of the pestle in DUALL $1 \mathrm{ml}$ tissue grinder (Kimble Chase Life Science and Research Products, Vineland, NJ, USA). After the phase separation of TRIzol reagent, the organic phase containing DNA and proteins was collected. DNA was then precipitated with ethanol and proteins were isolated from the phenol-ethanol supernatant. The proteins were then precipitated by isopropyl alcohol and pelleted at $12000 \times \mathrm{g}$ for $10 \mathrm{~min}$ at $+4{ }^{\circ} \mathrm{C}$. The protein pellet was washed 3 times with $0.3 \mathrm{M}$ guanidine hydrochloride solution in $95 \%$ ethanol and once with $99.5 \%$ ethanol. During the extraction pellets were grinded with pellet pestle in order to improve the solubility of the proteins. After each wash step, proteins were centrifuged $7500 \times \mathrm{g}$ for $5 \mathrm{~min}$ at $+4^{\circ} \mathrm{C}$. The air-dried protein pellet was dissolved in 2-DE rehydration buffer containing $9 \mathrm{M}$ urea, $2 \%$ (w/v) CHAPS, $0.5 \%$ (v/v) IPG buffer $\mathrm{pH} 4-7$ and $5 \mathrm{mg} / \mathrm{ml}$ DTT (added as fresh). The protein concentration of sample was measured using the Bradford method. The samples were stored at $-80^{\circ} \mathrm{C}$.

\section{Protein separation with 2-DE}

Proteins were separated by standard 2-DE. Briefly, the first dimension was performed in IPGphor ${ }^{\mathrm{TM}}$ (GE Healthcare, UK) isoelectric focusing (IEF) apparatus. Linear, $24 \mathrm{~cm}$ long, pH 4-7 Immobiline ${ }^{\mathrm{TM}}$ DryStrip gels (IPG-strips, GE Healthcare, UK) were rehydrated in the strip holders for 4 hours in $0.45 \mathrm{ml}$ rehydration buffer containing $9 \mathrm{M}$ urea, $2 \%(\mathrm{w} / \mathrm{v}$ ) CHAPS, 0.5\% (v/v) IPG-buffer $\mathrm{pH} 4-7,1.2 \%$ $(\mathrm{v} / \mathrm{v})$ DeStreak ${ }^{\mathrm{TM}}$ reagent, a trace of bromophenol blue and $150 \mu \mathrm{g}$ of total amount of protein. IEF was carried out at $+20^{\circ} \mathrm{C}$ using following step-and-hold settings: $50 \mathrm{~V}, 8 \mathrm{~h}$; $100 \mathrm{~V}, 1 \mathrm{~h} ; 500 \mathrm{~V}, 1 \mathrm{~h} ; 1000 \mathrm{~V}, 1 \mathrm{~h} ; 2000 \mathrm{~V}, 1 \mathrm{~h} ; 8000 \mathrm{~V}$, until $95000 \mathrm{Vh}$ was achieved. Then, the IPG-strips were incubated at room temperature in equilibration buffer (50 mM Tris- $\mathrm{HCl}, \mathrm{pH} 8.8,6 \mathrm{M}$ urea, 30\% (v/v) glycerol, $2 \%(\mathrm{w} / \mathrm{v})$ SDS, a trace of bromophenol blue, and $10 \mathrm{mg} /$ $\mathrm{ml} \mathrm{DTT}$ ) for $15 \mathrm{~min}$ and for another $15 \mathrm{~min}$ in the same buffer that contained $25 \mathrm{mg} / \mathrm{ml}$ of iodoacetamide instead of DTT. The second-dimension separation was performed using 9\%SDS-PAGE gels. Electrophoresis was carried out at $+10^{\circ} \mathrm{C}$ using an $\operatorname{Ettan}^{\mathrm{TM}}$ DALTsix electrophoresis unit (GE Healtcare) at a constant power of $3.5 \mathrm{~W} /$ gel for $0.5 \mathrm{~h}$ and then $13 \mathrm{~W} /$ gel until the dye front reached the bottom of the gel (about $4 \mathrm{~h}$ ). The ready gels were silver stained to visualize protein spots. Stained gels were scanned into computer using GS-710 Calibrated Imaging Densitometer (Bio-Rad Laboratories, Hercules, CA, USA). The gels were analyzed using PDQuest 7.2 software (Bio-Rad).

\section{Abbreviations}

CHAPS, 3-[(3-Cholamidopropyl)dimethylammonio]-1propanesulfonate; 2-DE, 2-dimensional electrophoresis; DTT, dithiothreitol; EA.hy926, human endothelial cell line; ICNIRP, International Commission on Non-Ionizing Radiation Protection; IEF, isoelectric focusing; IPG, immobilized $\mathrm{pH}$ gradient; MCF-7, human breast adenocarcinoma cell line; pI, isoelectric point; RF-EMF, radiofrequency modulated electromagnetic field; SAR, specific absorption rate; SDS, sodium dodecyl sulfate; SDS-PAGE, sodium dodecyl sulfate polyacrylamide gel electrophoresis; Tris-HCl, Tris(hydroxymethyl)aminomethane hydrochloride; 


\section{Authors' contributions}

AK executed the proteomics experiments and performed analysis of the proteomics data. $\mathrm{RN}$ assisted in designing of the study, participated in writing the grant funding the study, assisted in analysis of proteomics data. SH performed statistical analysis of the data. DL conceived and designed the study, obtained grant funding the study, coordinated execution and analysis of the results and wrote the draft manuscript. All authors participated in the writing of the final version of the manuscript, read it and approved it.

\section{Acknowledgements}

We thank Dr. J. Halttunen (Central Hospital of the University of Helsinki) for taking skin biopsies. Funding was provided by Tekes - Finnish Funding Agency for Technology and Innovation (HERMO project) and by STUKRadiation and Nuclear Safety Authority.

\section{References}

I. Krewski D, Glickman BW, Habash RW, Habbick B, Lotz WG, Mandeville R, Prato FS, Salem T, Weaver DF: Recent advances in research on radiofrequency fields and health: 200I-2003. J Toxicol Environ Health B Crit Rev 2007, 1 0:287-318.

2. Seitz H, Stinner D, Eikmann T, Herr C, Röösli M: Electromagnetic hypersensitivity (EHS) and subjective health complaints associated with electromagnetic fields of mobile phone communication - a literature review published between 2000 and 2004. Science of Total Environment 2005, 349:45-55.

3. Leszczynski D, Joenväärä S: Proteomics: new way to determine possible biological effects of mobile phone radiation. Nature Genetics 2001:67.

4. Leszczynski D, Joenväärä S, Reivinen J, Kuokka R: Non-thermal activation of the hsp27/p38MAPK stress pathway by mobile phone radiation in human endothelial cells: molecular mechanism for cancer- and blood-brain barrier-related effects. Differentiation 2002, 70:120-129.

5. Leszczynski D, Nylund R, Joenväärä S, Reivinen J: Applicability of discovery science approach to determine biological effects of mobile phone radiation. Proteomics 2004, 4:426-431.

6. Nylund R, Leszczynski D: Proteomics analysis of human endothelial cell line EA.hy926 after exposure to GSM 900 radiation. Proteomics 2004, 4: I359-1365.

7. Nylund $\mathrm{R}$, Leszczynski D: Mobile phone radiation causes changes in gene and protein expression in human endothelial cell lines and the response seems to be genome- and proteome-dependent. Proteomics 2006, 6:4769-4780.

8. Toivonen T, Toivo T, Puranen L, Jokela K: Setup and dosimetry for exposure of human skin in vivo to RF-EMF at $900 \mathrm{MHz}$. Bioelectromagnetics 2007 in press. DOI 10.1002/bem.20383

9. Zeng Q, Chen G, Weng Y, Wang L, Chiang H, Lu D, Xu Z: Effects of global system for mobile communications $1800 \mathrm{MHz}$ radiofrequency electromagnetic fields on gene and protein expression in MCF-7 cells. Proteomics 2006, 6:4732-4738.

10. Li HW, Yao K, Jin HY, Sun LK, Lu DQ, Yu YB: Proteomic analysis of human lens epithelial cells exposed to microwaves. Jpn J Ophtalmol 2007, 51:412-416.

II. Leszczynski D: Mobile phone radiation and gene expression. Radiation Res 2007, 167:121.

12. Leszczynski D: The need for a new approach in studies of the biological effects of electromagnetic fields. Proteomics 2006, 6:467l-4673.

13. Leszczynski D, Meltz ML: Questions and answers concerning applicability of proteomics and transcriptomics in EMF research. Proteomics 2006, 6:4674-7.

14. World Health Organization: WHO Research Agenda for Radio Frequency Fields 2006 [http://www.who.int/peh-emf/research/
rf research agenda 2006.pdf].

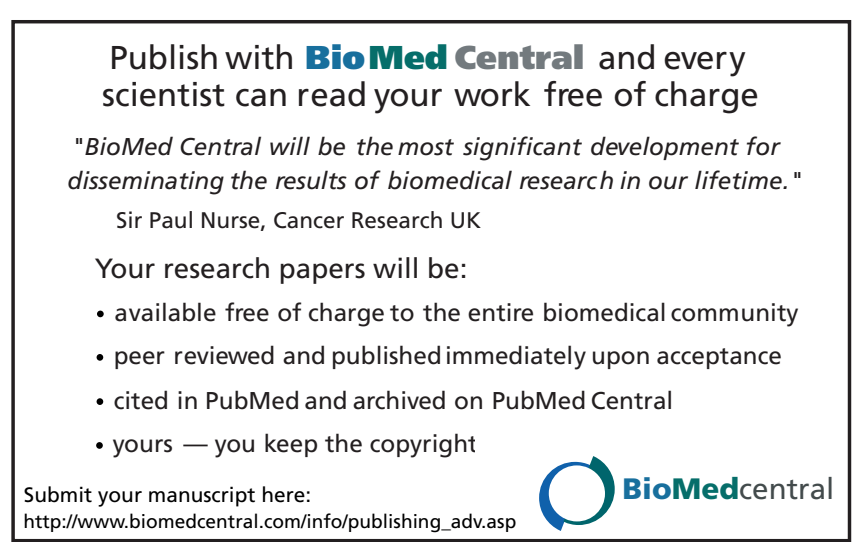

